\title{
CHẤN THƯƠNG, VẾT THƯƠNG ĐộNG MẠCH NGOẠI VI: HÌNH THÁI TỔN THƯO'NG VÀ KẾT QUẢ ĐIỀU TRI TẠI BỆNH VIỆN VIỆT ĐỨC
}

\author{
Đoàn Quốc Hung*, Nguyễn Văn Đại**, Nguyễn Thế May**
}

\section{TÓM TẮT}

$533 \mathrm{BN}$ điều trị tại BV Việt Đức từ 1/2010 đến 12/2014. Mô tả hồi cứu đánh giá kết quả phẫu thuật CT-VT ĐM ngoại vi, các biến chứng và cách xử trí. Vị trí tổn thương hay gặp nhất là ĐM cánh tay $30 \%(160 \mathrm{BN})$ và $Đ M$ khoeo $32,8 \%$ $(175 \mathrm{BN})$. Tổn thương giải phẫu bệnh chủ yếu là đứt đôi $\mathrm{ĐM}(189 \mathrm{BN} \approx 35,4 \%)$ và đụng dập $(262 \mathrm{BN} \approx 49,1 \%)$. Biện pháp điều trị chủ yếu với VT đứt đôi ĐM là nối trực tiếp 76,1\% (144/189) và ghép mạch tự thân $51,9 \%$ (136/262) với mạch đụng dập. Vị trí có tổn thương cắt cụt chi cao nhất là ĐM khoeo 66,6\% (10/15). Kết quả điều trị tốt sau mổ là $88,4 \%$, chỉ có $0,8 \%$ có biến chứng phải cắt cụt chi thì hai. Tỷ lệ tốt sau mổ ở nhóm VTĐMNV là 91,6 \% cao hơn so với nhóm CTĐMNV là 84,1\%. Biến chứng sau mổ hay gặp là nhiễm trùng vết mổ gặp 33/63, cắt cụt chi thì hai $15 / 63 \mathrm{BN}(23,8 \%)$

SUMMARY: Including 533 patients treated at the Viet Duc Hospital from 1/2010 to 12/2014. Retrospective study evaluated the results of treatment, complications and management in peripheral arterial injuries. Total arterial resection was seen in $189 / 533 \mathrm{pts} \approx 35,4 \%$ and arterial contusion in 262/533pts $\approx 49,1 \%$. The most frequent surgical treatment was resection-direct anastomosis in 76,1\% (144/189pts) and autologue veine graft 51,9\% (136/262). Brachial artery was the most popular artery which was atteint $(30 \% \approx 160 / 533 \mathrm{pts})$ and popliteal artery in $32,8 \%$ $(175 / 533)$. The highest rate of amputation concerned with popliteal lesion $(66,6 \% \approx 10 / 15 \mathrm{pts})$. Good post operative treatment accounted for $88,4 \%$, only $0,8 \%$ had complications with the secondary amputation. The good result $(91,6 \%)$ in arterial wound was more favorable in comparision with those of arterial contusion $(84,1 \%)$. Postoperative complications were local infection (33/63pts), secondary amputation $(23,8 \% \approx 15 / 63 \mathrm{pts})$.

\section{I. ĐẠT V VẤN ĐỀ}

Chấn thương-vết thương mạch máu (CTVTMM) ngoại vi là một cấp cứu ngoại khoa thường gặp chiếm $2 \%$ cấp cứu ngoại chung và $3,1 \%$ cấp cứu ngoại chấn thương. Chẩn đoán sớm, cấp cứu đúng quy trình, phẫu thuật kịp thời trong 6 giờ đầu sau tai nạn là những yếu tố quan trọng làm giảm các biến chứng, di chứng. Chẩn đoán muộn, xử trí không đúng dẫn đến các biến chứng do thiếu máu chi không hồi phục như mất chức năng chi do hoại tử một phần cơ hoặc cắt cụt chi do hoại tử hoàn toàn chi thể, nặng nhất là tình trạng nhiễm trùng nhiễm độc toàn thân gây suy đa tạng, tử vong. Có nhiều tiến bộ trong chẩn đoán và điều trị tại bệnh viện Việt Đức cũng như bệnh viện các tuyến, tuy nhiên tại bệnh viện Việt Đức là tuyến cuối cùng tiếp nhận các tổn thương mạch máu, trong những năm gần đây dù đã áp dụng nhiều biện pháp nhằm cải thiện chẩn đoán và điều trị bệnh nhân chấn thương-vết thương mạch máu, tuy nhiên dường như chưa được như mong muốn, đồng thời với thực trạng số lượng bệnh nhân ngày một nhiều, mức độ nặng của bệnh ngày một tăng. Vì vậy chúng tôi nghiên cứu đề tài này để nhận xét về

\footnotetext{
* Bệnh viện Bệnh viện HN Việt Đức

**Bệnh viện HN Việt Tiệp Hải Phòng

Nguoòi chịu trách nhiệm khoa học: PGS.TS. Đoàn Quốc Hung Ngày nhận bài: 10/02/2017 - Ngày Cho Phép Đăng: 10/03/2017

Phản Biện Khoa học: PGS.TS. Đặng Ngọc Hùng GS.TS. Lê Ngọc Thành
} 
hình thái tổn thương và kết quả điều trị sớm CTVT mạch máu ngoại vi giai đoạn 2010-2014, rút ra một số kinh nghiệm trong chẩn đoán và điều trị bệnh lý thường gặp và nguy hiểm này

\section{II. ĐỐI TƯợNG VÀ PHƯƠNG PHÁP} NGHIÊN CÚU

\section{1. Đối tượng}

Gồm 533 bệnh nhân (BN) bị CT-VT động mạch ngoại vi được mổ tại Bệnh viện Hữu nghị Việt Đức từ tháng 1/2010 đến tháng 12/2014 với chẩn đoán sau mổ là: chấn thương hoặc vết thương động mạch ngoại vi.

\subsection{Phương pháp nghiên cứu}

Mô tả hồi cứu, trên cơ sở thống kê các số liệu, đánh giá các tổn thương giải phẫu bệnh và xử trí trong mổ, đánh giá kết quả điều trị sớm, các biến chứng và xử trí các biến chứng.

Chỉ tiêu nghiên cứu gồm: giải phẫu bệnh, lâm sàng, chẩn đoán hình ảnh, phương pháp phẫu thuật, kết quả, biến chứng, tử vong, cắt cụt. Các số liệu thông kê bằng phần mềm thống kê $\mathrm{y}$ sinh học. Bàn luận, so sánh đối chiếu với các tác giả khác đã công bố.

\section{KẾT QUẢ NGHIÊN CÚU}

\subsection{Các hình thái tổn thương động mạch-xử trí}

Bảng 3.1. Hình thái tổn thương động mạch-xư trí

\begin{tabular}{|l|c|l|l|l|l|l|l|l|}
\hline Xử trí & $\begin{array}{l}\text { Nối } \\
\text { trực } \\
\text { tiếp }\end{array}$ & $\begin{array}{l}\text { Khâu } \\
\text { vết } \\
\text { thương } \\
\text { bên }\end{array}$ & $\begin{array}{l}\text { Ghép } \\
\text { mạch } \\
\text { tự thân }\end{array}$ & $\begin{array}{l}\text { Lấy } \\
\text { máu cục } \\
\text { + bóc } \\
\text { áo } \\
\text { ngoài }\end{array}$ & $\begin{array}{l}\text { Thắt } \\
\text { mạch }\end{array}$ & $\begin{array}{l}\text { Cắt } \\
\text { cụt } \\
\text { chì thì } \\
\text { đầu }\end{array}$ & $\begin{array}{l}\text { Mở } \\
\text { khoang }\end{array}$ & Tổng \\
\hline Đứt đôi ĐM & $\mathbf{1 4 4}$ & 0 & 33 & 0 & 11 & 1 & 0 & 189 \\
\hline VT bên ĐM & 20 & 20 & 8 & 0 & 2 & 0 & 0 & 50 \\
\hline Mất đoạn ĐM & 2 & 0 & 10 & 0 & 0 & 3 & 0 & 15 \\
\hline $\begin{array}{l}\text { Co thắt đụng dập } \\
\text { ĐM }\end{array}$ & 88 & 0 & $\mathbf{1 3 6}$ & 23 & 2 & 9 & 4 & 262 \\
\hline Phồng ĐM & 0 & 0 & 3 & 0 & 1 & 0 & 0 & 4 \\
\hline $\begin{array}{l}\text { Thông động tĩnh } \\
\text { mạch }\end{array}$ & 0 & 0 & 1 & 0 & 1 & 0 & 0 & 2 \\
\hline $\begin{array}{l}\text { Huyết khối tắc } \\
\text { dộng mạch }\end{array}$ & 3 & 0 & 3 & 3 & 0 & 1 & 1 & 11 \\
\hline Tổng & 257 & 20 & 194 & 26 & 17 & 14 & 5 & 533 \\
\hline
\end{tabular}

Hình thái tổn thương ĐM gặp chủ yếu là đứt đôi ĐM chiếm 35,45\% (189/533) và co thắt đụng dập ĐM chiếm 49,15\%(262/533). Biện pháp điều trị ngoại khoa chủ yếu đối với vết thương đứt đôi ĐM là nối trực tiếp chiếm $76,19 \%$ (144/189) và với co thắt đụng dập ĐM là ghép mạch tự thân chiếm $51,9 \%(136 / 262)$. 


\subsection{Liên quan vị trí tổn thương động mạch và cắt cụt chi}

Bảng 3.2. Vị trí tổn thương động mạch và cắt cụt chi

\begin{tabular}{|l|c|c|}
\hline Vị trí & Số bệnh nhân & Số bệnh nhân cắt cụt chi thì đầu \\
\hline Nách & 20 & 1 \\
\hline Cánh tay & $\mathbf{1 6 0}$ & 1 \\
\hline Quay & 35 & 0 \\
\hline Trụ & 12 & 0 \\
\hline Chậu ngoài & 9 & 0 \\
\hline Đùi & 84 & 1 \\
\hline Khoeo & $\mathbf{1 7 5}$ & $\mathbf{1 0}$ \\
\hline Chày trước & 22 & 1 \\
\hline Chày sau & 16 & 1 \\
\hline Tổng & 533 & 15 \\
\hline
\end{tabular}

Vị trí tổn thương ĐM hay gặp nhất là ĐM cánh tay chiếm 30,01\% (160/533) và ĐM khoeo chiếm $32,83 \%(175 / 533)$. Nhưng vị trí mà có tổn thương cắt cụt chi cao nhất là ĐM khoeo chiếm $66,67 \%(10 / 15)$.

\subsection{Kết quả điều trị sớm}

Bảng 3.3. Kết quả điều trị sớm bệnh nhân chấn thưong vết thương động mạch

\begin{tabular}{|l|l|c|c|}
\hline \multicolumn{2}{|l|}{ Kết quả điều trị } & $\mathbf{N}$ & $\%$ \\
\hline \multicolumn{1}{|l|}{ Tốt } & $\mathbf{4 7 0}$ & $\mathbf{8 8 , 2}$ \\
\hline \multirow{3}{*}{ Trung bình } & Nhiễm trùng & 35 & 6,6 \\
\cline { 2 - 4 } & Tắc mạch & 13 & 2,4 \\
\cline { 2 - 4 } & Hạn chế vận động & 6 & 1,1 \\
\cline { 2 - 4 } & Chèn ép khoang & 5 & 0,9 \\
\cline { 3 - 4 } & Cắt cụt chi thì 2 & 4 & 0,8 \\
\hline \multirow{3}{*}{ Kém } & Tổng & 533 & 100 \\
\hline & & & \\
\hline
\end{tabular}

Kết quả điều trị sớm chủ yếu là tốt chiếm 88,2\%(471/533). Kết quả kém có 4 bệnh nhân chiếm $0,8 \%(8 / 533)$ phải cắt cụt thì 2 . 
Bảng 3.4. Kết quả điều trị sớm bệnh nhân vết thuơng động mạch ngoại vi

\begin{tabular}{|c|c|c|c|}
\hline \multicolumn{2}{|c|}{ Kết quả điều trị } & $\mathbf{n}$ & $\%$ \\
\hline \multicolumn{2}{|c|}{ Tốt } & 263 & 91,6 \\
\hline \multirow[t]{4}{*}{ Trung bình } & Nhiễm trùng & 11 & 3,8 \\
\hline & Tắc mạch & 5 & 1,7 \\
\hline & Hạn chế vận động & 2 & 0,7 \\
\hline & Chèn ép khoang & 5 & 1,7 \\
\hline \multirow[t]{2}{*}{ Kém } & Cắt cụt chi thì 2 & 1 & 0,3 \\
\hline & Tổng & 287 & 100 \\
\hline
\end{tabular}

Kết quả tốt chiếm tỉ lệ cao nhất là 91,6\%(263/287) và cắt cụt chi thì 2 chỉ có 1 trường hợp chiếm $0,3 \%(1 / 287)$.

Bảng 3.5. Kết quả điều trị sớm bệnh nhân chấn thương động mạch ngoại vi

\begin{tabular}{|c|c|c|c|}
\hline \multicolumn{2}{|c|}{ Kết quả điều trị } & $\mathbf{n}$ & $\%$ \\
\hline \multicolumn{2}{|l|}{ Tốt } & 207 & 84,1 \\
\hline \multirow[t]{4}{*}{ Trung bình } & Nhiễm trùng & 24 & 9,8 \\
\hline & Tắc mạch & 8 & 3,3 \\
\hline & Hạn chế vận động & 4 & 1,6 \\
\hline & Chèn ép khoang & 0 & 0 \\
\hline \multirow[t]{2}{*}{ Kém } & Cắt cụt chi thì 2 & 3 & 1,2 \\
\hline & Tổng & 246 & 100 \\
\hline
\end{tabular}

Kết quả tốt chiếm tỉ lệ cao nhất là $84,1 \%(207 / 246)$ và cắt cụt chi thì 2 có 3 trường hợp chiếm $1,2 \%(3 / 246)$.

Bảng 3.6. Các biến chứng sớm sau mổ

\begin{tabular}{|l|c|c|}
\hline Biến chứng sớm & $\mathrm{n}$ & Tỷ lệ(\%) \\
\hline Nhiễm trùng vết mổ & $\mathbf{3 5}$ & $\mathbf{5 5 , 6}$ \\
\hline Tắc mạch & 13 & 20,6 \\
\hline Hạn chế vận động & 6 & 9,5 \\
\hline HCK( mở cân thì 2) & 5 & 7,9 \\
\hline Chảy máu & 0 & 0 \\
\hline Thiếu máu không hồi phục chi (cắt cụt thì 2) & 4 & 6,4 \\
\hline Tổng & 63 & 100 \\
\hline
\end{tabular}


Tổng số bệnh nhân có biến chứng chiếm $11,8 \%(63 / 533)$. Biến chứng hay gặp nhất là nhiễm trùng vết mổ chiếm 55,6\% (35/63). Có 04 trường hợp đã cố gắng phục hồi lưu thông mạch để bảo tồn chi, nhưng trong quá trình theo dõi thấy thiếu máu chi không hồi phục phải cắt cụt chi thì hai chiếm $6,4 \%$ trong các biến chứng.

\section{BÀN LUẬN}

\subsection{Các hình thái tổn thương động mạch và cách xử trí trong mổ}

Hình thái tổn thương ĐM gặp chủ yếu là đứt đôi ĐM chiếm 35,45\% (189/533)và co thắt đụng dập ĐM chiếm 49,15\%(262/533). Biện pháp điều trị ngoại khoa chủ yếu đối với vết thương đứt đôi ĐM là nối trực tiếp chiếm 76,19\% (144/189) và với co thắt đụng dập ĐM là ghép mạch tự thân chiếm $51,9 \%(136 / 262)$ vì đối với chấn thương ĐMNV do đụng dập tổn thương mạch đoạn dài $>2 \mathrm{~cm}$ nên cần loại bỏ đoạn $\mathrm{ĐM}$ tổn thương, do mất đoạn dài nên phải ghép mạch tự thân, thường dùng bằng tĩnh mạch hiển.

Vị trí tổn thương ĐM hay gặp nhất là ĐM cánh tay chiếm $30,01 \%(160 / 533)$ và ĐM khoeo chiếm 32,83\%(175/533). Nhưng vị trí mà có tổn thương cắt cụt chi cao nhất là ĐM khoeo chiếm $66,67 \%(10 / 15)$ ( Bảng 3.2). Vì khi có tổn thương ĐM khoeo thường là sau một chấn thương rất mạch, gây tắc không hoàn toàn $Đ M$, sau đó sự phát triển huyết khối lớn dần làm tắc hoàn toàn $\mathrm{ĐM}$, hơn nữa vùng gối vòng nối rất kém và thường kèm theo tổn thường phần mềm rộng( tuần hoàn phụ) nên tỉ lệ cắt cụt chi cao.

4.2. Kết quả điều trị sớm, các biến chứng và cách xử trí các biến chứng.

\subsubsection{Kết quả điều trị sớm}

Kết quả điều trị chấn thương, vết thương động mạch ngoại vi phụ thuộc vào nhiều yếu tố như : hình thái, vị trí tổn thương, tổn thương phối hợp, phương pháp sơ cứu ban đầu, thời gian từ lúc bị tai nạn đến lúc được phẫu thuật, trang thiết bị, khả năng gây mê hồi sức, kinh nghiệm của phẫu thuật viên khi đánh giá và xử trí thương tổn trong mổ, thể trạng của bệnh nhân...

Trong nghiên cứu của chúng tôi, kết quả điều trị tốt sau mổ chiếm tỷ lệ $88,2 \%$, chỉ có $0,8 \%$ có biến chứng phải cắt cụt chi thì hai do những chấn thương, vết thương ĐMNV đến muộn chúng tôi đã cố gắng lập lại lưu thông mạch hi vọng bảo tồn được tối đa phần chi thể nhưng trong quá trình chăm sóc, theo dõi thấy chi diễn biến thiếu máu chi không hồi phục phải cắt cụt chi thì hai (bảng 3.3).

Tỷ lệ tốt sau mổ ở nhóm VTĐMNV là 91,6 $\%$ cao hơn so với nhóm CTĐMNV là $84,1 \%$ (Bảng 3.4, 3.5). Điều này là do VTĐMNV chẩn đoán dễ và sớm hơn $C T Đ M N V$ và chủ yếu dựa vào lâm sàng: vết thương chảy máu thành tia và trên đường đi của động mạch, dấu hiệu thiếu máu cấp tính chi, mạch ngoại vi yếu hoặc mất.

\subsubsection{Các biến chứng và xử trí các biến chúng}

Bảng 3.6 cho thấy biến chứng sau mổ hay gặp là nhiễm trùng vết mổ gặp 35/63 các trường hợp biến chứng $(55,6 \%)$, chủ yếu là do tổn thương nặng tổ chức phần mềm, cơ và tuần hoàn phụ, mép da tiếp tục hoại tử và nhiễm trùng. Tỷ lệ phải cắt cụt chi thì 2 là $4 / 63$ các trường hợp $(6,4 \%)$ gặp phần lớn trong chấn thương động mạch và đến muộn, cố gắng phục hồi lưu thông mạch để theo dõi khả năng bảo tồn chi.

\section{KẾT LUẬN}

Hình thái tổn thương ĐM gặp chủ yếu là đứt đôi ĐM chiếm 35,45\% (189/533)và co thắt đụng dập ĐM chiếm 49,15\%(262/533). Biện pháp điều trị ngoại khoa chủ yếu đối với vết thương đứt đôi ĐM là nối trực tiếp chiếm 76,19\% (144/189) và với co thắt đụng dập ĐM là ghép mạch tự thân chiếm 51,9\%(136/262), Vị trí tổn thương ĐM hay gặp nhất là ĐM cánh tay chiếm 30,01\% (160/533) và ĐM khoeo chiếm 32,83\%(175/533). Nhưng vị trí mà có tổn thương cắt cụt chi cao nhất là $\mathrm{ĐM}$ khoeo chiếm 66,67\%(10/15).

Trong nghiên cứu của chúng tôi, kết quả điều 
trị tốt sau mổ chiếm tỷ lệ $88,2 \%$, chỉ có $0,8 \%$ có biến chứng phải cắt cụt chi thì hai do những chấn thương, vết thương ĐMNV đến muộn. Tỷ lệ tốt sau mổ ở nhóm VTĐMNV là 91,6 \% cao hơn so với nhóm CTĐMNV là $84,1 \%$. Biến chứng sau mổ hay gặp là nhiễm trùng vết mổ gặp 35/63 các trường hợp biến chứng $(55,6 \%)$, chủ yếu là do tổn thương nặng tổ chức phần mềm, cơ và tuần hoàn phụ, mép da tiếp tục hoại tử và nhiễm trùng. Tỷ lệ phải cắt cụt chi là $4 / 63$ các trường hợp $(6,4 \%)$ gặp phần lớn trong chấn thương động mạch và đến muộn, cố gắng phục hồi lưu thông mạch để theo dõi khả năng bảo tồn chi.

\section{TÀI LIỆU THAM KHẢO}

1. Nguyễn Hữu Ước, Chế Đình Nghĩa, và cộng sự (2007). Đánh giá tình hình cấp cứu chấn thương-vết thương mạch máu ngoại vi tại bệnh viện Việt Đức giai đoạn 2004-2006. Tạp chí ngoai khoa, 57(4), 20-25.

2. Lê Ngọc Thành (2003), Vết thương mạch máu ngoại vi, Bài giảng ngoại khoa, Đại học Y Hà Nội, Hà Nội.

3. Đoàn Quốc Hưng, Lê Ngọc Thành, Đặng
Hanh Sơn, et al. (1996). Vết thương mạch máu ngoại vi thời bình tại bệnh viện Việt Đức (1/1990-6/1995) Tạp chí ngoại khoa, 26(4), 9-14.

4. Đặng Hanh Đệ (2011), Phẫu thuật mạch máu nguyên tắc và kỹ thuật, Nhà xuất bản giáo dục, Hà Nội.

5. Bùi Đức Phú, Bùi Minh Thành (2006), Kết quả điều trị ngoại khoa vết thuoong động mach chi duoơi, Hội nghị ngoại khoa toàn quốc lần XII, Huế.

6. Netter Frank H. (2010), Atlas giải phẫu nguời, Nguyễn Quang Quyền dịch Nhà xuất bản Y học.

7. N. M. Rich, J. H. Baugh, C. W. Hughes (1970). Acute arterial injuries in Vietnam: 1,000 cases. Journal of Trauma-Injury, Infection, and Critical Care, 10(5), 359-369.

8. Đoàn Quốc Hưng, Dương Ngọc Thắng (2015). Kết quả điều trị chấn thương-vết thương động mạch ngoại vi giai đoạn 2010-2013. Tap chí $Y$ hoc thưc hàn,949,172-175. 